\title{
Modified Models and Database for Calculating Cooling Degree- Days for the Egyptian Climates
}

\author{
A. Khalil ${ }^{*}$, A. elsafty ${ }^{\dagger}$, I. Shabaka ${ }^{\ddagger}$
}

\begin{abstract}
Degree-days techniques are fundamental steady state methods for cooling frameworks analysis. The significance of such techniques shows up in the most recent couple of decades where vitality consumption increments altogether while the world energy assets turn out to be rare. Additionally, these techniques can provide a straightforward approach for the estimation of monthly or annual energy consumptions of air conditioning systems.

The issue of building up a cooling degree-days unit for summer air conditioning systems similar to that for heating system has been entangled by the way that energy consumption for summer air conditioning systems is influenced not just by sensible heat transmission (because of dry bulb temperature contrast) but additionally by latent heat load. Endeavors, have been done to make sense of a cooling degree-days unit by including the estimations of the inconvenience list (incorporates both dry bulb and wet bulb temperatures with certain weights) at different time periods daily, then subtracting certain value (usually called base temperature) from this sum. This requires comprehensive temperature records and does not take into account the internal sources of the latent loads (inhabitants, supplies, and so on). Another intricacy is the effect of solar radiation on cooling loads, which is not directly related to any of the ambient temperatures. Besides, many works exhibited comes about for cooling degree-days units utilizing wet bulb temperatures only.

In this work, cooling degree-days models are exhibited and connected to most cities in Egypt covering every climatic zone of the country. The models considers the impact of both the sensible heat transmission and the latent (inward and outside) cooling load. They additionally consider the impact of solar heat gain on the cooling degree-days unit. What's more, the impact of base temperature is examined. Correlations between the consequences of the introduced model and cooling degree-days units computed from direct surrounding temperature records are shown.
\end{abstract}

Keywords: Air conditioning, cooling degree-days, variable-base temperature, solar heat gain, sol air temperature, sensible and latent cooling loads, database.

\section{Nomenclature}

$\mathrm{T}_{\mathrm{m}} \quad$ Daily mean temperatures. , $\left({ }^{\circ} \mathrm{C}\right.$ or $\left.\mathrm{K}\right)$

$\mathrm{T}_{\mathrm{B}} \quad$ Base temperature, $\left({ }^{\circ} \mathrm{C}\right.$ or $\left.\mathrm{K}\right)$.

Member ASHRAE, Professor and Head; Mech. Power Eng. Dept., Tanta Uni., Tanta, Egypt; akhalileg@yahoo.com

$\dagger$ Professor and Dean, Mechanical Engineering, College of Engineering \& Technology, Kuwait; elsafty@hotmail.com

* PhD students, Mech. Power Eng. Dept., Tanta University, Tanta, Egypt; shabakagroup@gmail.com . 
$D_{c} \quad$ Cooling degree-days, $\left({ }^{\circ} \mathrm{C}\right.$ orK $)$.

$D_{c, y} \quad$ Yearly cooling degree-days, $\left({ }^{\circ} \mathrm{C}\right.$ orK $)$.

$\mathrm{D}_{\mathrm{C}, 1}$ Erbs Method for Estimating Cooling Degree-Days, $\left({ }^{\circ} \mathrm{C}\right.$ orK $)$.

$\sigma_{\mathrm{m}} \quad$ Monthly standard deviation.

$\sigma_{\mathrm{y}} \quad$ Yearly standard deviation.

$\mathrm{Nm}$ Number of days in the month.

$\mathrm{D}_{\mathrm{c}, 2}$ Schoenau-Kehrig DegreeDay, $\left({ }^{\circ} \mathrm{C}\right.$ orK $)$.

$\mathrm{S}_{\mathrm{d}} \quad$ Standard deviation

$\mathrm{Z}_{\mathrm{b}} \quad$ Contrast between base temperature

$\mathrm{f}$ Gaussian probability density function

F Equivalent cumulative normal probability function

$\mathrm{D}_{\mathrm{C}, 3}$ Monthly estimation of cooling degree-days, $\left({ }^{\circ} \mathrm{C}\right.$ orK $)$.

Ts Sol-air Temperature, , $\left({ }^{\circ} \mathrm{C}\right.$ orK $)$.

It Total solar radiation occurrence on surface $\left(\mathrm{W} / \mathrm{m}^{2}\right)$.

$\mathrm{D}_{\mathrm{c}, 4}$ Cooling Degree-Days induced latent wet blub temperature, $\left({ }^{\circ} \mathrm{C}\right.$ orK$)$.

$\mathrm{D}_{\mathrm{c}, 5}$ Sol-air Degree-days, $\left({ }^{\circ} \mathrm{C}\right.$ orK).

\section{Introduction}

Energy analysis assumes a critical part in building up an ideal and cost effective plan of HVAC system for a building. In spite of, the fact that there are different energy investigation strategies, which change in many-sided quality, the degree-day techniques are the least complex techniques and settled devices for energy examination if the structures utilize, the efficiency of HVAC system, indoor temperature and inner increases are moderately steady.

Khalil 2003 presented two methodologies for ascertaining cooling degree-days. The models require just the monthly normal surrounding temperatures and solar radiation as input. The primary approach, the sol-air approach, is a general one. It presented the effect of solar radiation on the building envelop, which spoke to a great part of buildings cooling loads for some areas. The approach did not require a particular characteristics or cooling loads of buildings. It additionally incorporated the impact of the genuine interaction of building encompass with the sky. The approach could be utilized for estimating measures of hotness and seriousness of atmospheres at various areas. It can be gainful for building cooling degree-days maps for various cities. There was a absence of data in the ASHRAE handbooks database for cooling degree-days for Egypt.

This approach might be utilized to fill this gap and give adequate data in this concern. The second approach concentrates on specific buildings and applications using the variable-base technique. Additionally, the sol-air idea and the ventilative cooling theory were conjugates of this approach. It helped HVAC\&R planners and building engineers in evaluating the monthly, regular and yearly energy required for their systems,[1].

Thevenard 2011 examined several methods for calculating heating and cooling degree-days to any base by relying on temperature statistics such as the monthly mean temperature and the standard deviation of daily average temperature. It was found that the method developed by Schoenau and Kehrig worked best, and was usually able to estimate monthly heating and cooling degree-days to within $3^{\circ} \mathrm{C} /$ day or $5.4^{\circ} \mathrm{F} /$ day (in a root mean-square error sense) of their true value. The method clearly outperforms other widely used methods, such as the one derived by Erbs et al. (1983). The paper also presented an extension of the Schoenau and Kehrig method to the case when only monthly mean temperatures were known. 
The performance of this hybrid model was not quite as good, with typical MBEs still less than $1.5^{\circ} \mathrm{C} /$ day $\left(2.7^{\circ} \mathrm{F} /\right.$ day $)$. On the other hand, RMSEs as high as $10^{\circ} \mathrm{C} /$ day $\left(18^{\circ} \mathrm{F} /\right.$ day $)$; however, this hybrid model still performs better than older models such as the Erbs et al. (1983) method recommended to use the full Schoenau and Kehrig (1990) model whenever the required inputs were available. The tables of climatic design conditions in the 2009 ASHRAE HandbookFundamentals list the necessary parameters for over 5400 locations worldwide,[2].

Ciulla et al 2015 presented degree-days is a climatic pointer that can be utilized as a part of the appraisal and examination of climate identified with energy consumption of structures. Basically, degree-days are a summation of the contrasts between the outdoor air temperature and some reference (or base) temperature over a specific time period.

In writing, unique strategy can be utilized for deciding the degree-days value and for the most part the decision relies on upon the accessibility of climatic information of every location. In this paper, after a review and examination of the most widely recognized methodologies used to decide degree-days, the Italian methodology was profoundly broke down. The utilization of Italian specialized principles depends on climate information computed on a monthly time arrangement observed before 1994. The out of date quality of the utilized climate information prompts to an inaccurate evaluation of energy exhibitions.

Considering the climatic change that in the most recent years has influenced Italy land, the point of the paper is to survey the effect of new degree-days. Thus, in this paper the creators recalculated degree-days of some Italian urban communities, considering the normal monthly temperatures of the most recent decade. Information was extricated from Meteonorm 7, a standout amongst the most well-known programming for the actual preparing of atmosphere information. Besides, different datasets were produced considering future situations characterized by IPCC (Intergovernmental Panel on Climate Change).

An examination with the official degree-days issued by current legislation and new degree-days recalculated with later information highlighted how environmental change has influenced the figuring of this parameter. Presentation the antagonistic impacts on the earth atmosphere because of the worldwide expanding requests of energy, have turned into the matter of sympathy toward individuals of over the world. The increase of air temperatures because of environmental change may imply that noteworthy 20 -year averages used for energy planning arranging won't be fitting and the rate of temperature ascend sooner rather than late energy budgets,[3].

The aim of this paper to make database for Egypt's nations for cooling degree-day by different strategies: a) simple degree day, b) Erbs technique, c) Schoenau-Kehrig mean temperature strategy and d) Enhanced Models for degree-day calculation. It helps planners and building engineers in evaluating the monthly, occasional and yearly energy requirements for HVAC\&R systems.

There are two methodologies for heating and cooling degree-days counts. The solair approach is a general one, which figures degree-days for any geographic location, slighting a specific building or application. It presents the impact of solar radiation on the encompassing temperatures on the building conceal and collaboration of building envelops with the outside environment. It is valuable for getting the cooling degree-days' maps for Egypt zones. It can be utilized for assessing helpful measures of heat and seriousness of atmospheres in various locations. The second approach is the variable-base approach. The variable-base technique can be conjugated with the sol air approach. It depends on the simplicity and accuracy of the mathematical model employed. 


\section{Weather Conditions}

Exact and dependable climate information is essential for building energy simulations and examinations. The climate information being utilized as a part of vitality investigation decides the exactness and attributes of the outcomes.

Therefore, the database utilized as a part of a vitality examination ought to cover a long period and depend on recent values. In this review, daily least and most extreme open-air dry-bulb temperatures of late years were utilized. The information acquired amid no less than 10 years were utilized as a part of the computations.

Daily mean temperatures were gotten by averaging the base and the extreme temperatures. The crude information were taken from, Weather Underground, 2017is a commercial weather service providing real-time weather information via the Internet. Weather Underground, 2017 provides weather reports for most major cities across the world on its website, as well as local weather reports for newspapers and websites,[4].

\section{Degree-Days Calculations}

\subsection{Cooling Degree-Days}

The estimation of the plain cooling degree-days $D_{c}\left({ }^{\circ} \mathrm{C}\right.$-day or K-day) is just characterized as the summation over a specific time of days $N$ of the positive distinction between the watched daily mean temperatures $T_{m}$ and the base temperature $T_{B}$, i.e.

$D_{c}=\sum_{1}^{N}\left(T_{m}-T_{B}\right)^{+}$

where the plus sign over the section demonstrates that positive values just are to be tallied. Every month might be spoken to by an average day. Equal results might be gotten by utilizing hourly temperature records $T_{o}$ and summing up the distinctions $\left(T_{o}-T_{b}\right)$ for the day, devided by 24 , then duplicating by the quantity of days $N$ of every month. This outcome in the monthly degree-days, while the yearly degree-days is gotten by including the estimations of all months together.

$$
D_{c, y}=\sum_{m o n t h s} D_{c, 1}
$$

The impact of base temperature on the monthly and yearly cooling degree-days for Egypt is considered.

\subsection{Erbs Method for Estimating Cooling Degree-Days}

The fundamental thought of the improved technique initially proposed by Erbs et al. (1983) is the suspicion that the outdoor ambient encompassing temperature for every month takes after a standard likelihood conveyance with a standard deviation $\sigma_{\mathrm{m}}$ and $\overline{T_{o, m}}$ an average temperature $\left({ }^{\circ} \mathrm{C}\right)$ For every month, the cooling degree days can be acquired as an element of $T_{b}\left({ }^{\circ} \mathrm{C}\right)$.

$$
\begin{aligned}
& D_{C, 1}=\sigma_{m} N_{m}^{\frac{3}{2}}\left[\frac{\theta_{m}}{2}+\frac{\ln \left(e^{-a_{m} \theta m}+e^{a_{m} \theta m}\right.}{2 \cdot a_{m}}\right] \\
& \theta_{m}=\frac{\overline{T_{o, m}}-T_{b}}{\sigma_{m} \cdot N_{m}^{\frac{1}{2}}}
\end{aligned}
$$


$N_{m}$ is the number of days in the month considered. For most areas, Erbs et al. (1983) found that the coefficient an and the standard deviation, $\sigma_{\mathrm{m}}$, can be evaluated utilizing the accompanying expression

$$
\begin{gathered}
a_{m}=1.698 \sqrt{N_{m}} \\
\sigma_{m}=1.45-0.029 \overline{T_{o, m}}+0.0664 \sigma_{y r} \\
\sigma_{y}=\sqrt{\frac{\sum_{m=1}^{12}\left(\overline{T_{o, m}}-\overline{T_{o, y r}}\right)^{2}}{12}}
\end{gathered}
$$

Annual degree-days can be acquired by including the monthly degree-days over the twelve months of the year,[5].

\subsection{Schoenau-Kehrig Method for Estimating Cooling Degree-Days}

This technique was produced by Schoenau and Kehrig ,Energy estimating and modelling methods in ASHRAE Handbook, 2009 and is one of the broadly embraced strategies, [6]. The equation for ascertaining monthly cooling degree-days, $D_{c, 2}$ to base $T_{b}$ is given by

$$
D_{c, 2}=N S_{d}\left[Z_{b} F\left(Z_{b}\right)+\mathrm{f}\left(Z_{b}\right)\right]
$$

Where $N$ is the number of days in the month, $Z_{b}$ is the contrast between base temperature, Tb and monthly mean temperature, $T_{m}$, standardized by the standard deviation $\left(S_{d}\right)$ of the everyday mean temperature, and $S_{d}$, which can be found from the accompanying expression:

$$
Z_{b}=\frac{T_{m}-T_{b}}{S_{d}}
$$

Function $f$ is the Gaussian probability density function with mean 0 and standard deviation $\left(S_{d}\right)$ equal to 1 , and function $F$ is the equivalent cumulative normal probability function:

$$
\begin{aligned}
& f(z)=\frac{1}{2 \prod} \mathrm{e}^{\left(-\frac{z^{2}}{2}\right)} \\
& F(z)=\int_{-\infty}^{z} f(z) d z
\end{aligned}
$$

\subsection{Enhanced Models for Degree-Day Calculation}

\subsubsection{Modified Solair Approach}

Cooling degree-days unit by adding up the values of the discomfort index (includes both dry bulb and wet bulb temperatures with certain weights) at different times daily, then subtracting certain value (usually called base temperature) from this sum.

This requires comprehensive temperature records and does not take into account the internal sources of the latent loads (occupants, equipments, etc). Some studies propose the introduction of the wet bulb temperature $T_{w}$ (dew point temperature may be used) into an equation for calculating cooling degree-days that accounts for both sensible and latent heat loads imposed by outside air ,[1] as follows

discomfort index $\left.\left.=0.4\left[\mathrm{~T}_{\mathrm{o}}+\mathrm{T}_{\mathrm{w}}\right]+15\right) / \mathrm{n}\right]-\mathrm{T}_{\mathrm{B}}$ 
Where temperature is simultaneous readings in ${ }^{\circ} \mathrm{F}$ and $\mathrm{n}$ is the number of time intervals of temperature readings during the day. The creator considers the presentation of the monthly mean wet-bulb temperature $T_{w}$ into a condition for computing cooling degree-days in another work. These records for both sensible and latent heat loads forced by outside air. Give us initial a chance to characterize the non-dimensional standardized scale variable equation (4). Substituting Equation (4) into Equation (1) yields the monthly estimation of cooling degreedays

$D_{C, 3}\left(T_{b}\right)=\sigma_{m} \theta^{+} N^{\frac{3}{2}}$

Where the plus sign above $\Theta$ indicates that positive values only are to be counted, i.e. negative values are considered zeros. The following simple formula is proposed as a good approximation of the cooling degree-days. Where $\alpha$ is a constant and has the units of (day/month) $)^{1 / 2},[8]$. Similar equations were used by the annual value $\mathrm{D}_{\mathrm{my}}$ is the sum of $\mathrm{D}_{\mathrm{m}}$ over the year,[7].

\subsubsection{Mean Wet Bulb Temperature}

Then introducing the mean wet-bulb temperature $T_{w}$ into a form like Equation (4) gives a simple formula is introduced using a normalized non-dimensional temperature scale variable that includes the ambient mean wet bulb temperature

$$
\Theta^{*}=\frac{[c(T m+T w)+8.3-T B]}{\sigma m N^{1} / 2}
$$

Where $\mathrm{c}$ is constant. Cooling degree-days is then calculated from

$$
\mathrm{D}_{\mathrm{c}, 4}=1 / 2 \sigma \mathrm{mN}^{\frac{3}{2}}\left[\Theta^{*}+\left[\ln \left(\mathrm{e} \alpha \Theta^{*}+\mathrm{e}-\alpha \Theta^{*}\right)\right] / \alpha\right]
$$

The constants $\mathrm{c}$ and $\alpha$ for Equations (14) and (15) are determined using temperature records for all cities. The constant $\alpha$ found in numerous conditions for figuring the cooling degree-days in this review is resolved numerically in view of a measure that locate the base root mean square of the deviation on a normal yearly premise, [7].

The ideal estimation of $\alpha$ is observed to be 4.887 with a normal least deviation in the request of $1.0 \%$. Additionally, the constant $\mathrm{c}$ found in the condition for figuring the standardized scale variable $\Theta$ is resolved in an indistinguishable path so from to represent the inactive cooling load forced by the outside air as indicated by the trademark climate of every city.

Numerical hunt prompted to ideal estimations of c of 0.398 for Alexandria, 0.418 for Tanta, 0.440 for Cairo, 0.471 for Assiut and 0.483 for Aswan. The annual value $D_{y c, 4}$ is the sum of $D_{c, 4}$ over the year. The advantages of using Equation (15) is its simplicity since its inputs are only the monthly mean dry and wet bulb temperatures and standard deviation of each location. In addition, it accounts for the latent cooling load of building imposed by the outside air,[6].

\subsubsection{Sol-air Temperature}

Mathematical statements (3), (13) and (15) express cooling degree-days that record just for the sensible heat part of the cooling load of a building. The impact of sunlight based radiation on building wrap is not considered in both of these mathematical statements. The sol-air temperature is the outdoor air temperature that without all radiation changes gives the same rate of heat transfer into the surface, as would the mix of episode incident solar radiation, radiant energy trade with the sky and other outdoor air surroundings, and heat exchange with the outside air. 
Expecting that the wall external surface temperature is equivalent to the surrounding mean temperature Tm, the energy balance of a sunlit wall would prompt the accompanying expression for the sol-air temperature $T_{s}$

$T_{s}=T_{m}+\frac{\alpha_{w}}{h_{o}} F_{c} I_{t}-\frac{\varepsilon_{w}}{h_{o}} \Delta R$

Where $\alpha_{\mathrm{w}}$ and $\varepsilon_{\mathrm{w}}$ are the wall absorptance for sun powered radiation and hemispherical emittance of surface, separately, It is the total solar radiation occurrence on surface, $\mathrm{W} / \mathrm{m}^{2} . F_{c}$ is the average clouding coefficient $\left(\mathrm{F}_{\mathrm{c}}\right.$ is a fraction between 0 and 1.0$), \mathrm{h}_{\mathrm{o}}$ is coefficient of heat transfer by long-wave radiation and convection at external wall surface, $W / m^{2} K$, and $\Delta R$ is the difference between long-wave radiation episode on surface from sky and surroundings and radiation transmitted by blackbody at outside air temperature, $\mathrm{W} / \mathrm{m}^{2}$. For effortlessness, $\Delta \mathrm{R}=$ $63 \mathrm{~W} / \mathrm{m}^{2}$ for horizontal surfaces that get sky radiation just. In this way, if $\varepsilon_{\mathrm{w}}=1$ and $\mathrm{h}_{\mathrm{o}}=16$ $\mathrm{W} / \mathrm{m}^{2} \mathrm{~K}$, the sky radiation rectification term (third term in the right hand-side of the above equation) will be $4 \mathrm{~K}$ for horizontal surfaces. Essentially, a sky radiation remedy term will be $1 \mathrm{~K}$ for vertical surfaces.

Presently, we can utilize the sol-air temperature acquired from equation (16) to get a cooling degree-days unit that produces into record the results of solar radiation on the external walls of a building. For sol-air approach, the computation is the same as the equations above, yet substitute sol-air temperature (Ts) rather than (Tm) in equation (15).

The upsides of utilizing equation below (17) are its effortlessness, precision and that it takes the building latent cooling load forced by the outside air into record. To get a cooling degreedays unit that produces into record the results of sunlight based radiation on the external dividers of a building. $T_{0}$ start with, we characterize the dimensionless standardized scale variable

$\Theta_{s}=\frac{1}{\sigma_{m} \sqrt{N}}\left[c\left(T_{s}+T_{w}\right)+8.3-T_{B}\right]$

At that point, a superior estimate of the cooling degree-days might be acquired utilizing

$D_{\mathrm{c}, 5}=1 / 2 \sigma \mathrm{m} N^{3 / 2}\left[\Theta_{\mathrm{s}}+\frac{1}{\alpha}\left[\ln \left(e^{\alpha \Theta_{\mathrm{s}}}+e^{-\alpha \Theta_{\mathrm{s}}}\right)\right]\right]$

\section{Results and Discussions}

It can be beneficial for expressing the hotness and severity of weather at any location. It may also helps in filling the gap found in different climatic data bases, like that of ASHRAE, due to the lack of the correct information concerning cooling degree-days.

The cooling degree-days $D_{c, 5}$ calculated using the sol-air approach, Eqs. (18) is plotted in Figure 1 to figure 9 for Tanta. The results are compared with those obtained without the sol-air concept; $D_{c}, D_{c, 1}$ and $D_{c, 4}$.

A comparison between $D_{c}, D_{c, 1}, D_{c .2}, D_{c, 3}$ shows good agreement, although they calculate the same variable from different equations. This agreement proves the validity and accuracy of the mathematical model of Eq . (3). In general, the average annual deviations between $D_{c}, D_{c, 1}, D_{c .2}$ ,$D_{c, 3}$ for Tanta are less than $1.8 \%$. The average annual deviation is about half this value at $T_{B}=$ $16{ }^{\circ} \mathrm{C}$ and becomes smaller at lower base temperatures. 


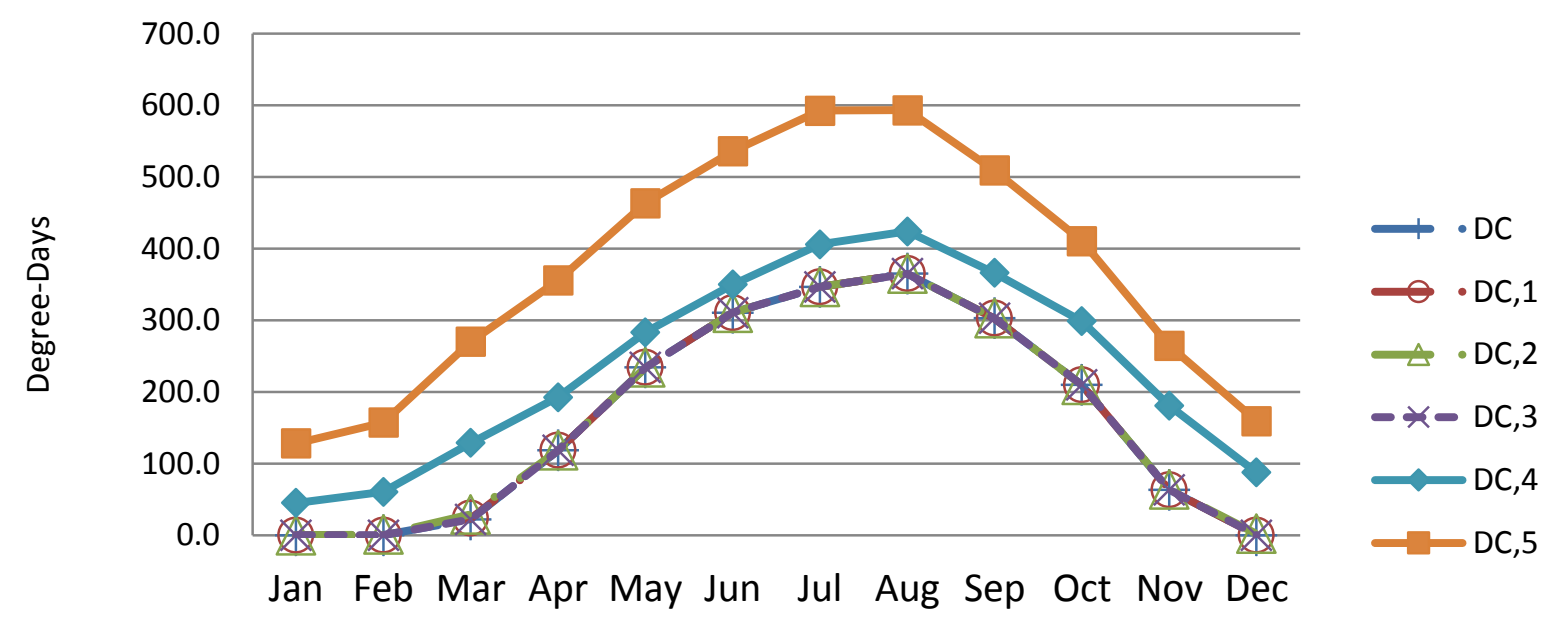

Fig. 1 Cooling Degree days at base temperature $18{ }^{\circ} \mathrm{C}$ for Tanta

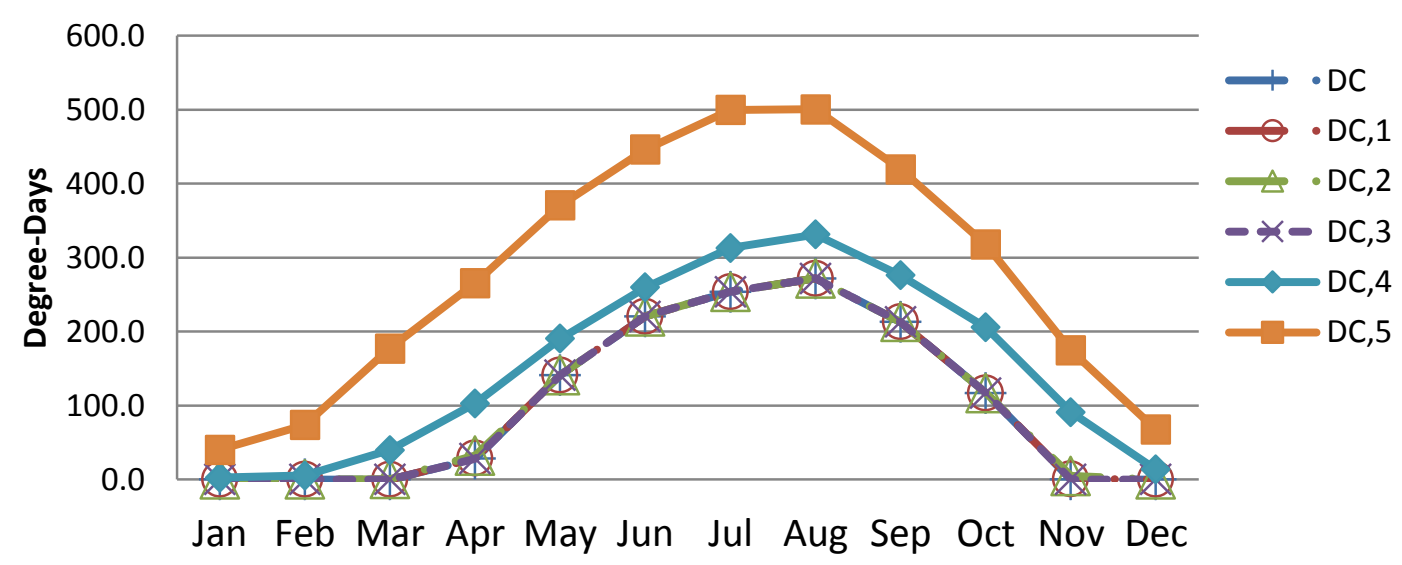

Fig. 2 Cooling Degree days at base temperature $21^{\circ} \mathrm{C}$ for Tanta

As shown from pervious figures that $D_{c}, D_{c, 1}, D_{c .2}$ and $D_{c, 3}$ are identical curves with different mathematical operations which shows us an great agreement about the results shown. Figure 1,2 and 8 show $D_{c}, D_{c, 4 a n d} D_{c, 5}$ with variable base temperature for Tanta ,respectively. Figure 3show us that when $\mathrm{T}_{\mathrm{b}}=16^{\circ} \mathrm{C}, \mathrm{D}_{\mathrm{c}}=487$ degree-days at August which is expected and agrees with characteristic weather of city. 


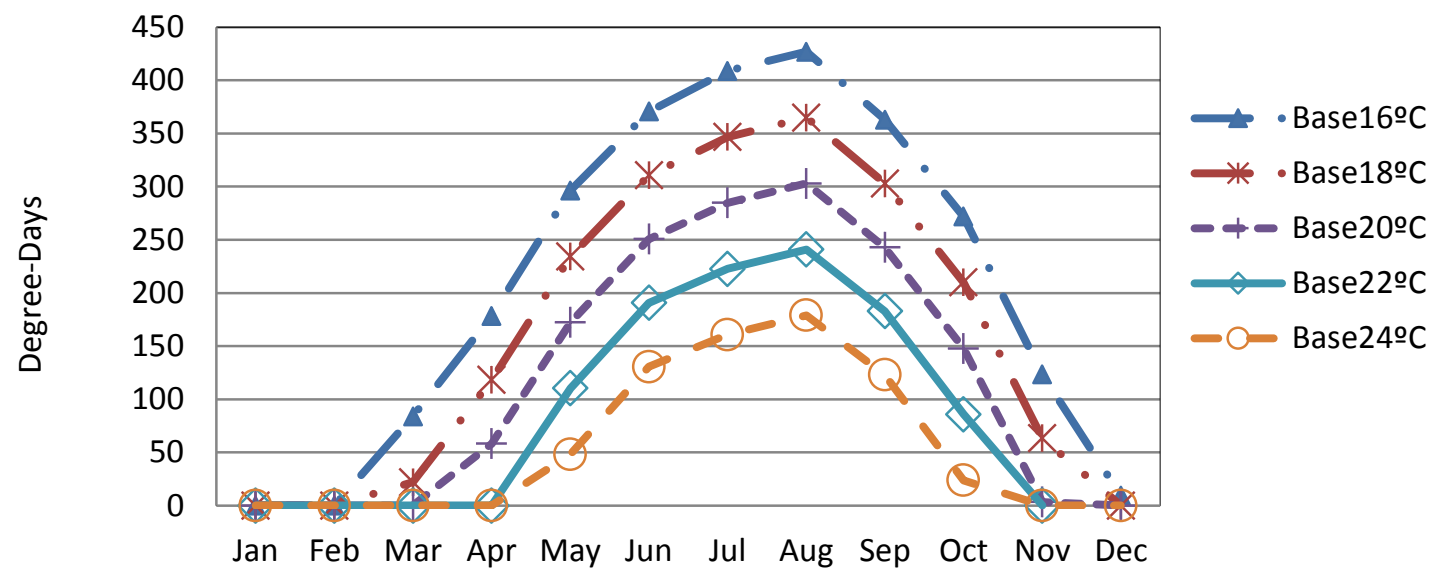

Fig. $4 D_{c}$ at Variable Base temperature for Tanta.

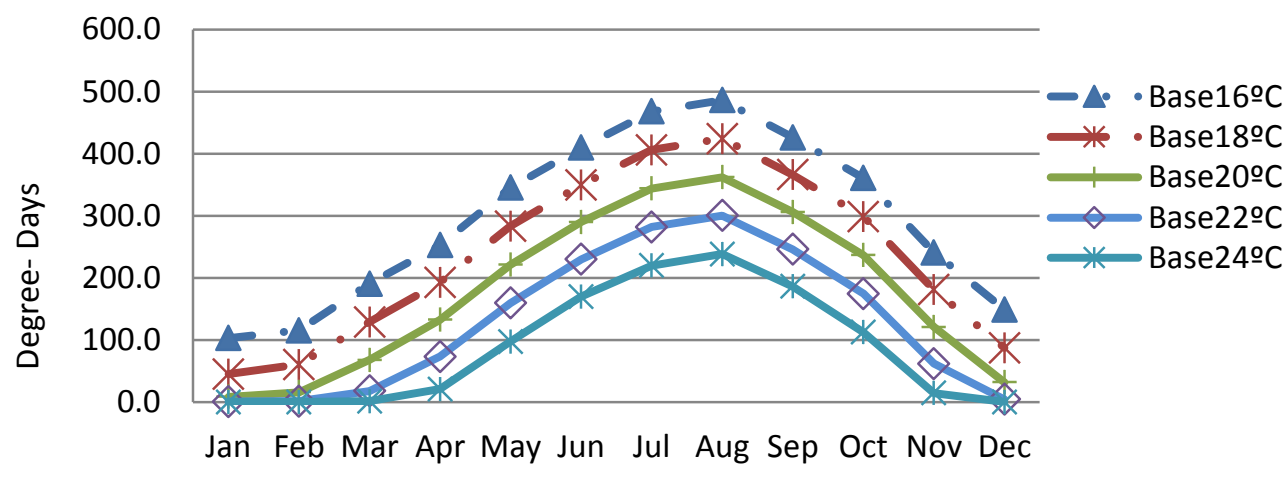

Fig. 5 Dc,4 at Varaiable Base temperature for Tanta.

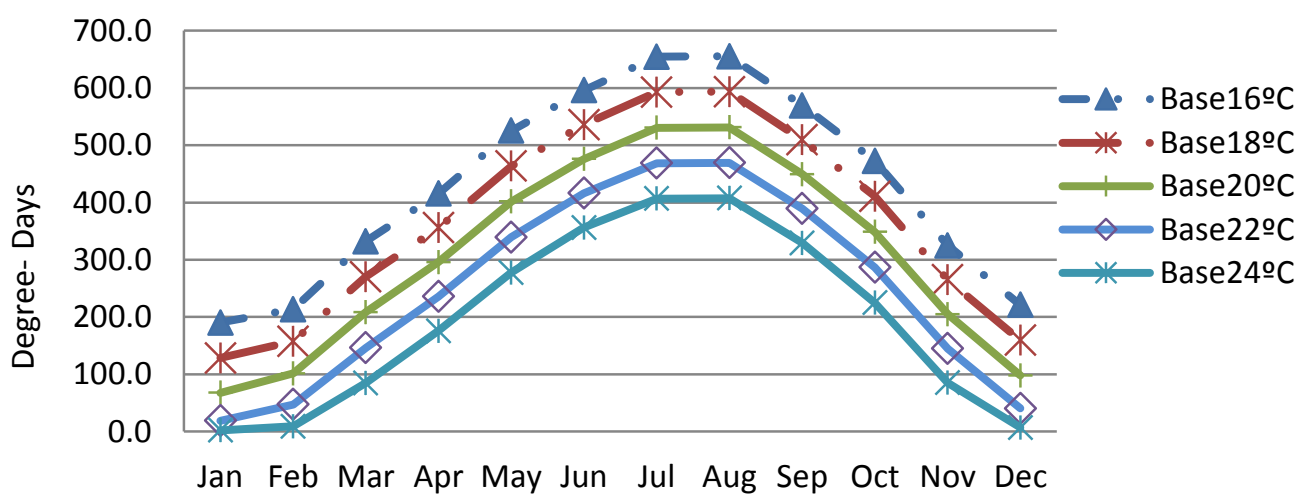

Fig. 6 DC,5 at Variable Base temperature for Tanta 
In view of the database for temperature appeared in (18) and utilizing Equations (3) and (18), cooling degree-days at $18^{\circ} \mathrm{C}$ for different location in Egypt for different methods were got.A comparison between $D_{c, 4}, D_{c}, D_{c, 1}, D_{c, 2}$ and $D_{c, 3}$ from Table1 shows that an increase of $15 \%$ to $44 \%$ in the cooling degree-days is due to the introduction of Tw, i.e. due to the latent load imposed by the outside air. This increase is maximum for Alexandria and decreases as we go south, and reaches its minimum at Aswan. This trend is expected and agrees with characteristic weather of each city.

These results are in good agreement with statistics of the external cooling load calculations for those cities. Comparing $D_{c, 5}$ and $D_{c, 4}$ shows that the introduction of the sol air temperature in cooling degree-days approach increases $\mathrm{D}_{\mathrm{c}, 4}$ with values of $35 \%$ to $45 \%$ at $\mathrm{T}_{\mathrm{B}}=18^{\circ} \mathrm{C}$.

Table 1 Cooling Degree-Days at $18^{\circ} \mathrm{C}$ for different location in Egypt with different methods.

\begin{tabular}{|l|l|l|l|l|l|l|l|l|}
\hline City & $\begin{array}{l}\text { Long., } \\
\mathrm{E}\end{array}$ & $\begin{array}{l}\text { Lat., } \\
\mathrm{N}\end{array}$ & $\mathrm{D}_{\mathrm{c}}$ & $\mathrm{D}_{\mathrm{c}, 1}$ & $\mathrm{D}_{\mathrm{c}, 2}$ & $\mathrm{D}_{\mathrm{c}, 3}$ & $\mathrm{D}_{\mathrm{c}, 4}$ & $\mathrm{D}_{\mathrm{c}, 5}$ \\
\hline Cairo & 31.3 & 30.1 & 1972.9 & 1974.8 & 1983.7 & 1972.9 & 2868.8 & 4861.7 \\
\hline Tanta & 31.0 & 30.8 & 1972.9 & 1974.8 & 1983.7 & 1972.9 & 2823.6 & 4441.7 \\
\hline Zagazig & 31.5 & 30.6 & 1972.9 & 1974.8 & 1983.7 & 1972.9 & 2823.6 & 4479.9 \\
\hline Giza & 31.2 & 30.0 & 1972.9 & 1974.8 & 1983.7 & 1972.9 & 2829.2 & 4508.1 \\
\hline Alex & 29.9 & 31.2 & 1478.2 & 1482.8 & 1496.5 & 1478.2 & 2717.9 & 3797.9 \\
\hline Aswan & 32.9 & 24.1 & 3377.4 & 3382.8 & 3397.2 & 3377.4 & 3563.7 & 6564.1 \\
\hline $\begin{array}{l}\text { Sharm } \\
\text { Sheik }\end{array}$ & 33.8 & 27.2 & 3070.4 & 3076.0 & 3085.9 & 3070.4 & 3256.6 & 5575.6 \\
\hline Hurghada & 33.8 & 27.2 & 2728.6 & 2734.5 & 2751.2 & 2728.6 & 3156.3 & 5888.4 \\
\hline Luxor & 32.7 & 25.7 & 2940.1 & 2948.6 & 2960.7 & 2940.1 & 3044.2 & 6309.1 \\
\hline $\begin{array}{l}\text { Marsa } \\
\text { Alam }\end{array}$ & 34.6 & 25.6 & 2859.5 & 2864.8 & 2874.6 & 2859.5 & 3154.4 & 6227.1 \\
\hline Port-Said & 32.3 & 31.3 & 1625.2 & 1630.4 & 1644.3 & 1625.2 & 3062.5 & 3828.2 \\
\hline $\begin{array}{l}\text { Marsa } \\
\text { Matruh }\end{array}$ & 27.2 & 31.4 & 1198.9 & 1203.1 & 1215.3 & 1198.9 & 2425.6 & 3388.6 \\
\hline Edfo & 32.9 & 25.0 & 2940.1 & 2948.6 & 2960.7 & 2940.1 & 3289.2 & 6084.8 \\
\hline Qena & 32.7 & 26.2 & 2940.4 & 2948.9 & 2961.0 & 2940.4 & 3288.4 & 5842.0 \\
\hline Ismailiya & 32.3 & 30.6 & 1625.2 & 1630.4 & 1644.3 & 1625.2 & 2677.5 & 4323.2 \\
\hline El Arish & 33.8 & 31.1 & 1304.4 & 1307.2 & 1318.7 & 1304.4 & 2543.5 & 4044.3 \\
\hline Siwa & 25.5 & 29.2 & 1467.5 & 1468.5 & 1476.6 & 1467.5 & 2686.3 & 5145.8 \\
\hline
\end{tabular}

The increase has the same trend at other base temperatures. This enhancement in the cooling degree-days unit is minimum for Alexandria and increases as we go south, and reaches its maximum at Aswan. This is an expected trend and agrees with the known weather characteristics. These results are al so in quite acceptable agreement with the statistics of the external cooling load calculations for those cities.

\section{Degree-Days Data Base}

To make the calculation amicable and time successful; a PC program is designed utilizing Matlab. To make the projects created easy to use sort GUI (graphic user interface) is created. So any individual without knowing the detail of the program can run. Also, this component it has two push catches, "Next" and 'Exit'. The Next button prompts to the rest of the parts of the program and 'Exit' button ends the program shown in figure 6 . The next module for computing 
'Input window' for selecting the city from List box and enter the the base temperature in Edit text box shown figrue8 appears.

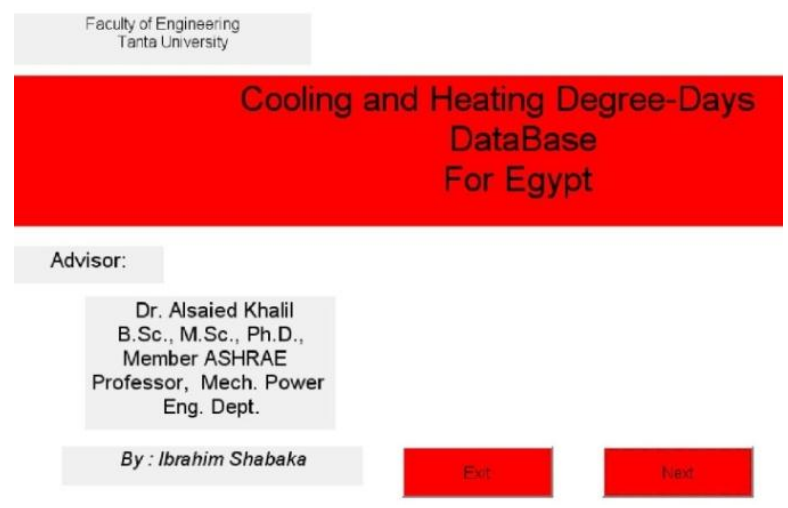

Fig. 6 Database starting window
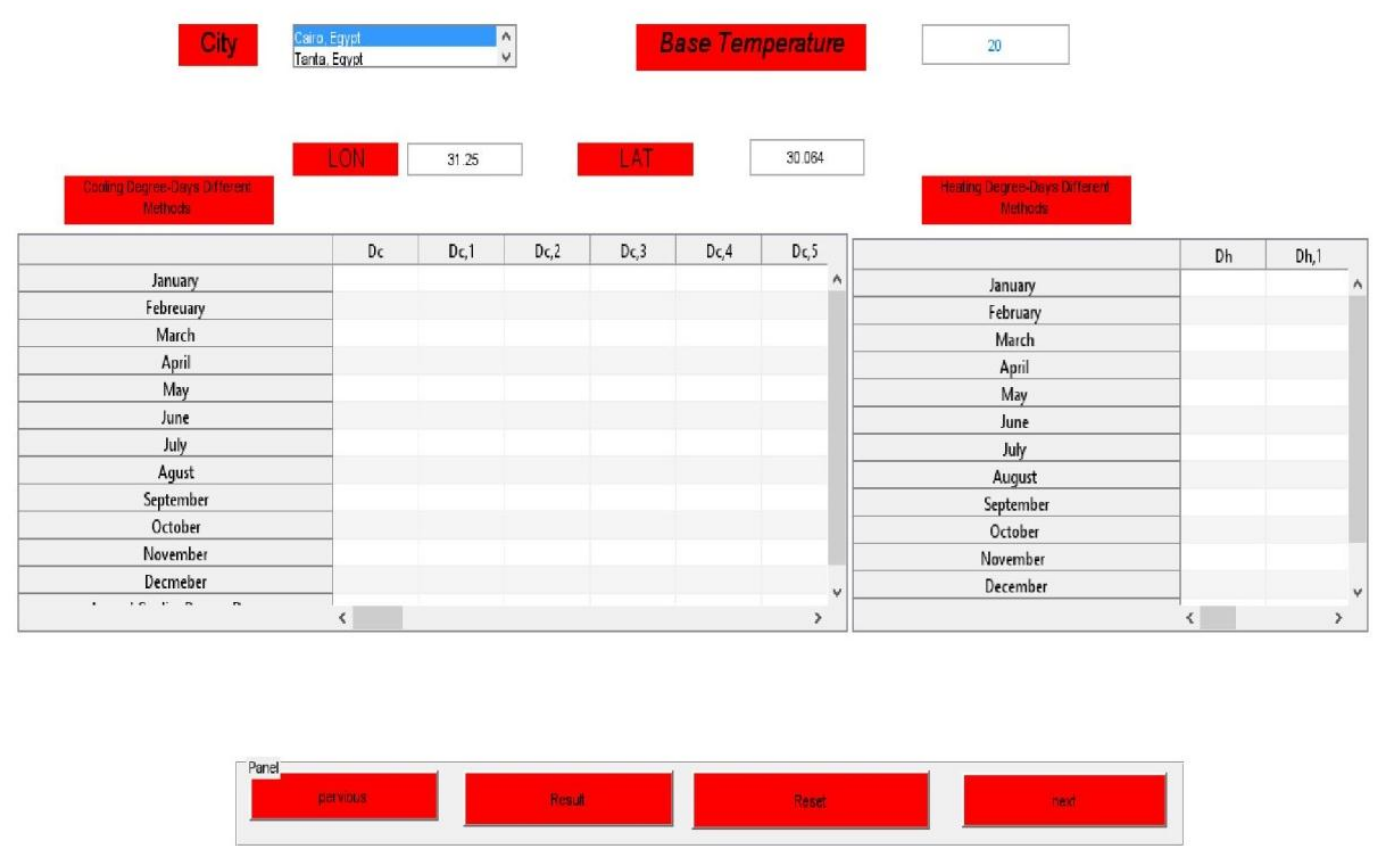

Fig. 7 'Input window' for selecting the city and base temperature

After user writes the base Temperature and selects 'Results button' in the program. The program will takes the given data then get the results in the same window for both cooling \& heating degree-days with different methods $D_{c}, D_{c, 1}, D_{c, 2}, D_{c, 3}, D_{c, 4}$ and $D_{c, 5}$ in tabular form in table1 and heating degree-days table2, as shown figure9. Moreover, when the user presses 'Next' button another the module gives the graphs comparison between all methods of cooling and heating degree-days.

When user presses 'cooling degree-days 'button as shown in Fig.10, if the users chooses 'heating degree-days' button, the graph will appear as shown in Fig.11(also, the heating degreedays calculation out of scope of this paper).

Finally, program can gives print of the table in excel program for all base temperature enter by the user. The graph compression between different variable different bases shown in figure 12. Which helps HVAC designer in estimating energy consumption. 

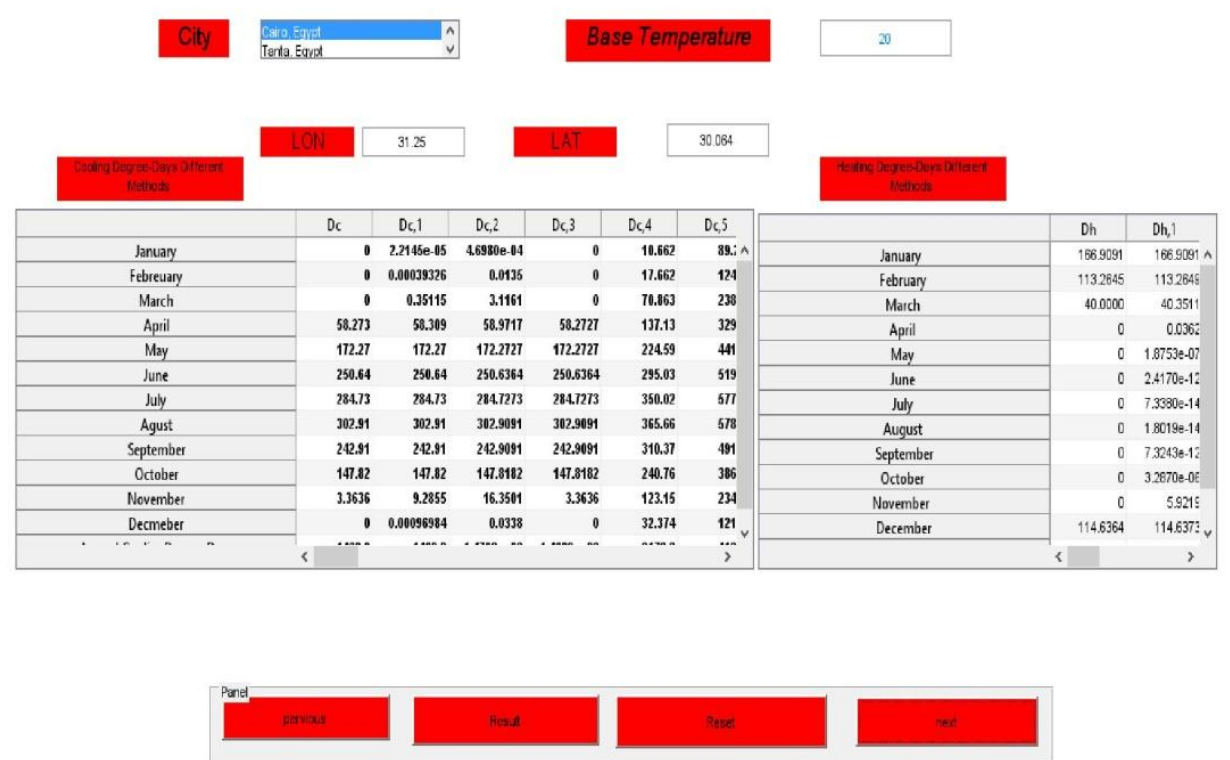

Fig. 8 Results for both Cooling and Heating Degree-Days Tabular Form
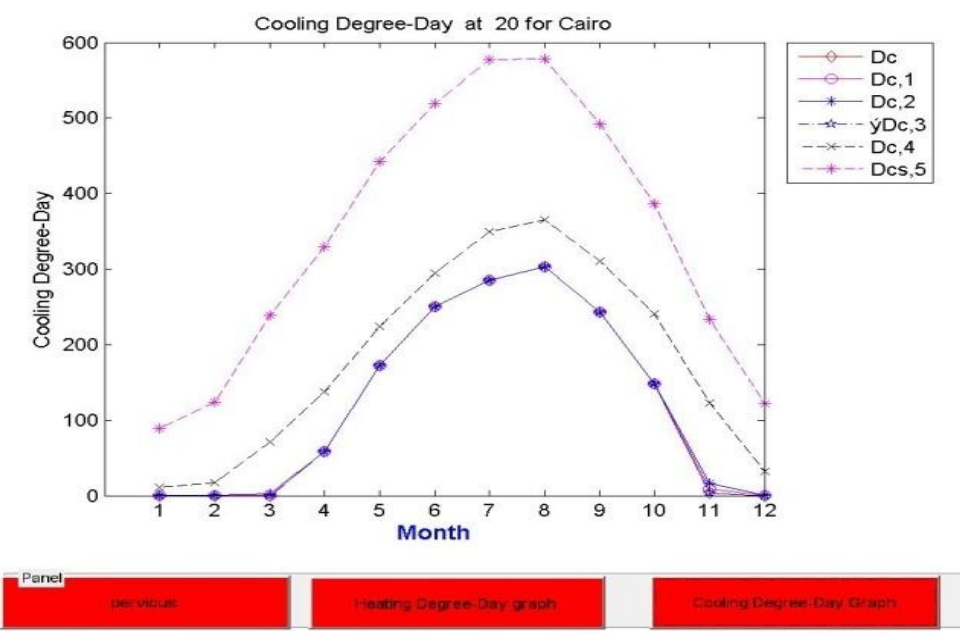

Fig. 9 Cooling Degree-Days Graph

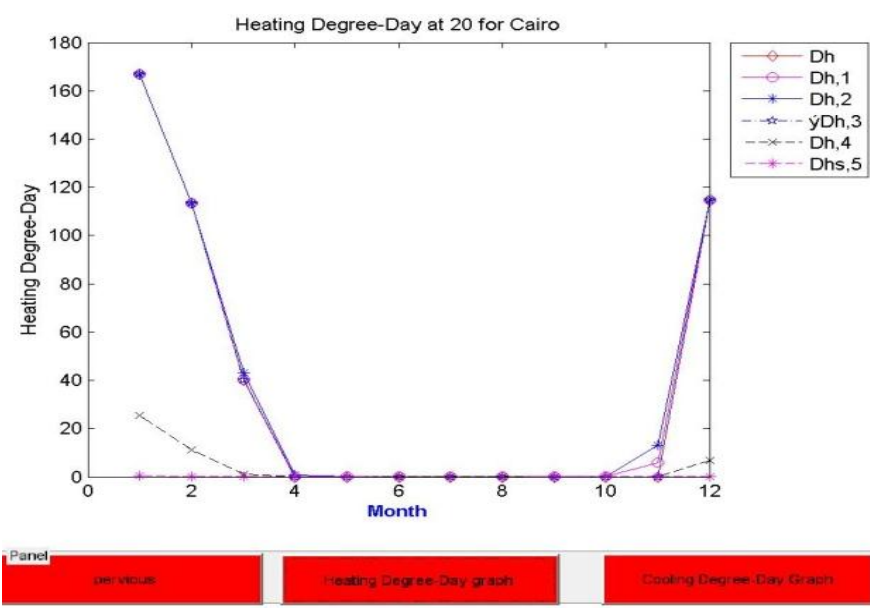

Fig. 10 Heating Degree-Days for Cairo at $T_{B}=20^{\circ} \mathrm{C}$ from database. 


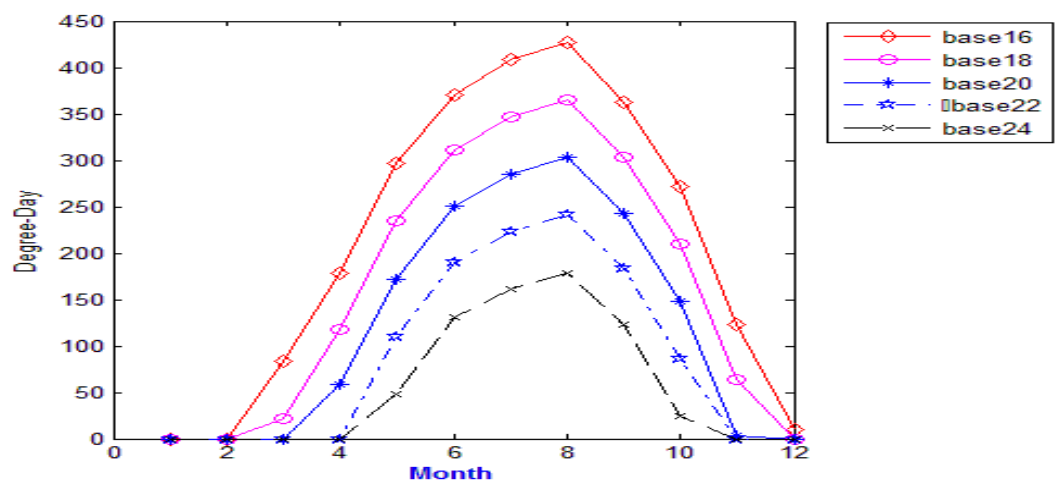

Fig. $11 D_{c}$ at Variable Base Temperature for Cairo at $T_{B}=20^{\circ} \mathrm{C}$ from database.

\section{Conclusion}

The calculation of cooling degree-days as a tool that may be used for calculating energy needs for cooling was examined in this paper. The cooling degree-days with variable-base temperatures for Tanta as well as some other cities in Egypt are calculated using long-term measured data.

Base temperatures of 16 to $24^{\circ} \mathrm{C}$ are selected in the calculation of cooling degree-days. Annual as well as monthly cooling degree-days are presented in Figured form for Tanta using different mathematical and physical models. Average annual cooling degree-day is connected to the base temperature with an association coefficient of 0.9885. Calculations are done to highlight the impact of base temperature on energy savings.

A database is used for calculation of cooling as well as heating degree-days for any location in Egypt at any base temperature. The database is programmed in Matlab in an easy and user friendly interface. It can be used for comparison between different models for calculation of degree-days for different locations and different base temperature during different periods.

\section{References}

[1] Khalil, A. (6-8 September, 2003). Cooling degree-Days for the Egyptian Climates, ASHRAE RAL Conference. Energy Conservation and Environmental Aspects of Buildings, Cairo, Egypt.

[2] Didier Thevenard Member ASHRAE. ( 2011 ). Methods for Estimating Heating and Cooling Degree-Days to Any Base Temperature. ASHRAE Transactions, Volume 117.

[3] Ciulla; G., Lo Brano V. and Moreci E. (13 May 2015). Degree Days and Building Energy Demand. Third Southern African Solar Energy Conference (pp. 65-75). Kruger National Park, South Africa: SASEC2015.

[4] Steremberg; Alan, Jeff Masters, Chris Schwerzler. (2017, January 31). Weather Underground. Retrieved January 1, 2017, from

https://www. wunderground.com/airport/HECA/2017/2/28

[5] American Society of Heating, R. a.-C. (2001). ASHRAE Handbook of Fundamentals. Atlanta, GA.: ASHRAE Handbook of Fundamentals.

[6] Handbook, A. (2009). Energy estimating and modelling methods in ASHRAE Handbook. ASHRAE Handbook.

[7] Khalil, A. (July 2004). Modified Solair and Variable-Base Cooling Degree-Days Approaches. Journal of Engineering Sciences, Assiut University, Vol. 32, No. 3, pp. 1435 $-1453$. 